\title{
Solar Heat Pipe for Greenhouse Application in the Arctic Regions: A Case Study
}

\author{
Ryan Cain, Casey Hoflich, Joseph Ofeldt, Karlin Swearingen, Sunwoo Kim \\ Mechanical Engineering, University of Alaska, Fairbanks \\ P.O. Box 755905, Fairbanks, Alaska 99775-5905, USA \\ racain@alaska.edu; caseyhoflich@gmail.com; jlofeldt@alaska.edu; ksweari2@alaska.edu; swkim@alaska.edu
}

\begin{abstract}
Rural communities throughout arctic and subarctic regions of the world have difficulties providing cost-effective means of growing produce during the winter months. Plants need light and heat in order to survive and grow, both of which are in short supply during the long, cold winters. The average temperature of the spring and fall seasons in Fairbanks, Alaska is only about 30 to $40^{\circ} \mathrm{F}$, which provides unreliable conditions to grow most crops. The traditional growing season in northern areas is roughly four months long, which is too short for many plants to grow and/or produce fruit. The purpose of the present research is to evaluate the use of solar heat pipe vacuum collectors to elongate the growing season of greenhouses in the arctic regions. The greenhouse utilizes the collection and retention of solar heat and a thermal mass to store the heat during days and release during nights. The solar heat pipe captures solar radiation, which heats a water- propylene glycol mix to act as the carrying medium. This fluid is pumped into the adjacent greenhouse and through the thermal mass unit. The thermal mass consists of two concrete slabs and dissipates the stored heat to normalize temperature fluctuations between night and day. A test greenhouse was built with dimensions of $12 \mathrm{ft}$ by $10 \mathrm{ft}$ with a height of 6 to $8 \mathrm{ft}$ in Fairbanks, Alaska. Data collections for a performance analysis were made in April 2017. The experiments showed that the temperature of the greenhouse was above $60^{\circ} \mathrm{F}$, at an external temperature of $32^{\circ} \mathrm{F}$. The solar heat pipe with thermal mass system increased the average greenhouse temperature by $11^{\circ} \mathrm{F}$.
\end{abstract}

Keywords: Solar Heat Pump, Greenhouse, Extended Season, Heat Transfer.

\section{Introduction}

Residents of arctic and subarctic climate must overcome unique challenges in life. One of these is the scarcity of food and the difficulty in growing or raising it. Sunrays striking the Earth's surface are less concentrated at higher latitudes, so even during the long, polar days energy from the sun is limited. The average temperatures during the shoulder seasons of spring and fall are about 30 to $40^{\circ} \mathrm{F}$ [1], which is not suitable to grow most crops. Many northern populations also lived nomadic lifestyles just a century or two ago, gathering food and resources from many different places. Nowadays, with the influences of Western society and modern technology, permanent settlements have become the norm, and this shift in lifestyles has been difficult to maintain. Arctic and subarctic climates cannot generally sustain the biomass necessary to grow crops or raise livestock. This has caused many communities in rural Alaska to shift from self-sustaining to relying on imported goods [2]. Furthermore, northern biomes grow notoriously slow and have a low concentration of biomass. The need for more available food has driven an emigration from rural areas to more metropolitan ones [3]. These northern communities have started building passive greenhouses and large gardens in an effort to increase local food production.

Passive greenhouses rely on solar energy for heat and light, rather than on external sources such as propane and fluorescent light bulbs. The use of this technology in the Arctic is still in its infancy. Traditional gardens and greenhouses are only effective during the warm, short summers, and communities that rely on them are only able to grow plants with short growing seasons, such as kale and cabbage. Root vegetables, such as potatoes, turnips, and carrots can also be grown, even into the fall, as they are more resistant to the cold. This limited selection understandably falls well short of nutritional and caloric needs.

There are several passively heated greenhouse designs currently used in the arctic and subarctic regions of Alaska and other countries [4-7]. Some regions also use systems that store thermal energy during the day in order to offset freezing temperatures at night. The systems heat the ground below the greenhouse (or sometimes a large concrete slab) by pumping warm air down during the day and letting the heat dissipate by night [7]. This strategy, however, is not practical in remote, 
northern climates. Much of northern Alaska, for example, is permafrost. Such a system would thaw the surrounding ground, leaving the greenhouse floating in a thermokarst lake. The logistics of digging a foundation in remote villages is also a downside.

In order to best address the specific problems and constraints of an extended season greenhouse, the present work examined the use of a solar heat pipe vacuum collector and thermal mass. Solar energy collection is achieved by means of the evacuated vacuum tube solar collector. Solar energy is captured by heat pipes contained within the evacuated tubes of the thermal collector and in turn, transferred to a water/propylene glycol mix, which is then pumped through the greenhouse. The liquid then transfers the captured heat as it flows through concrete slabs, placed beneath the planter beds, which serve as the thermal mass. Incorporation of a control system allows for the regulation of fluid flow and keeps the greenhouse within the specified temperature range. A test greenhouse was built with dimensions of $12 \mathrm{ft}$ by $10 \mathrm{ft}$ with a height of 6 to $8 \mathrm{ft}$ in Fairbanks, Alaska. Data collections for a performance analysis were made in April 2017. The heat collection performance of the solar heat pipe and the temperature rise due to the heat stored in the thermal mass were evaluated.

\section{Building of Test Greenhouse}

Figure 1 is a photograph of the test greenhouse built in Fairbanks Alaska. The greenhouse utilizes the collection and retention of solar heat and a thermal mass to store the heat during days and release during nights. The solar heat pipe captures solar radiation, which heats a water- propylene glycol (50 volume $\%$ - 50 volume $\%$ ) mix to act as the carrying medium. This fluid is pumped into the adjacent greenhouse and through the thermal mass unit. The thermal mass consists of two concrete slabs and dissipates the stored heat to normalize temperature fluctuations between night and day. In order to best collect this sunlight, an east-to-west orientation that utilizes a clear, or glazed, south-facing wall was decided. Following a common rule of adding $10^{\circ}$ to the site location's latitude [8], the ideal pitch of the south wall is $75^{\circ}$. However, since this angle is very close to $90^{\circ}$, a vertical south-facing wall was adopted for ease of build. The glazing is single walled, corrugated polycarbonate panels, which allow for approximately $90 \%$ of light transmission. The floor of the greenhouse as well as the north, east, and west walls were constructed with layers of insulation. The dimensions of the greenhouse were set at $12 \mathrm{ft}$ by $10 \mathrm{ft}$ with a $6 \mathrm{ft}$ tall north facing wall and a peak height of $8 \mathrm{ft}$. Walls of the greenhouse were constructed using the standard $2 \mathrm{ft}$ by $4 \mathrm{ft}$ construction walls. For the purpose of this greenhouse, a commercial solar heat pipe vacuum collector, Apricus ETC-30, was selected [9]. The solar heat pipe consists of the manifold and the 30 heat pipes that are enclosed with vacuum tubes. The 88.4 in wide and 79 in high structure provides a gross area of $47.33 \mathrm{ft}^{2}$ and aperture area of $30.77 \mathrm{ft}^{2}$. The maximum operation pressure and stagnation temperature are $116 \mathrm{psi}$ and $442^{\circ} \mathrm{F}$.

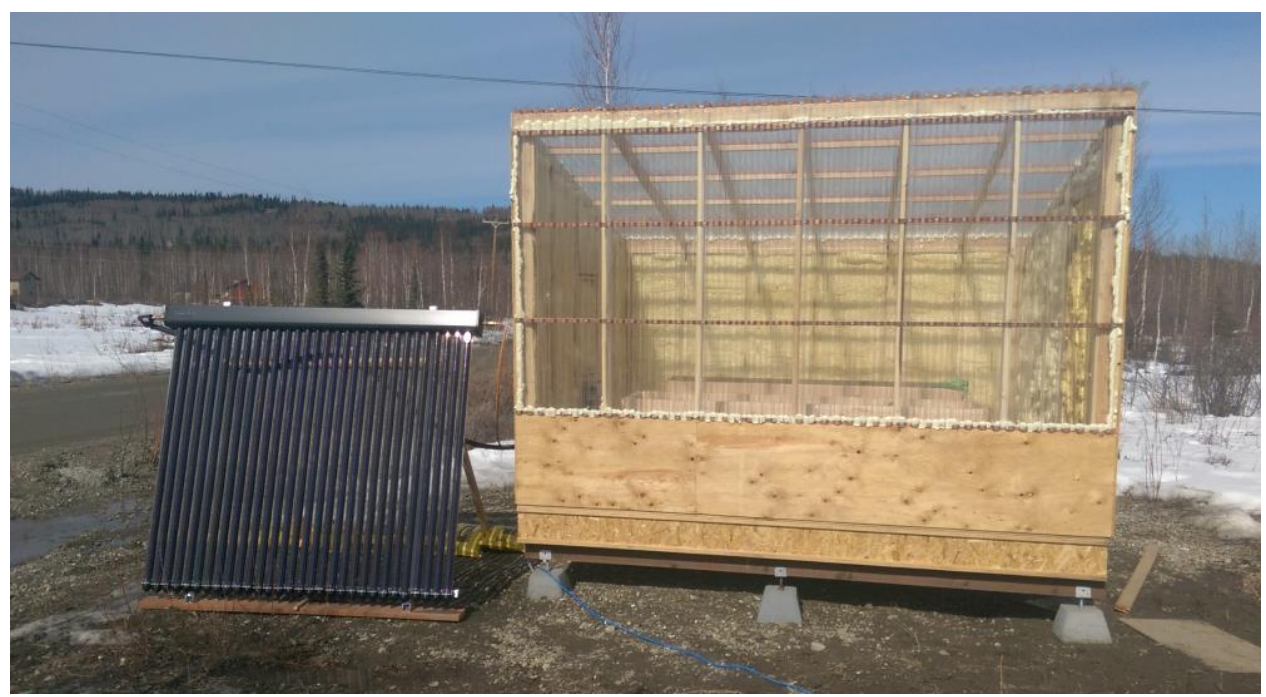

Fig. 1: Photograph of the greenhouse and the solar heat pipe vacuum collector. 


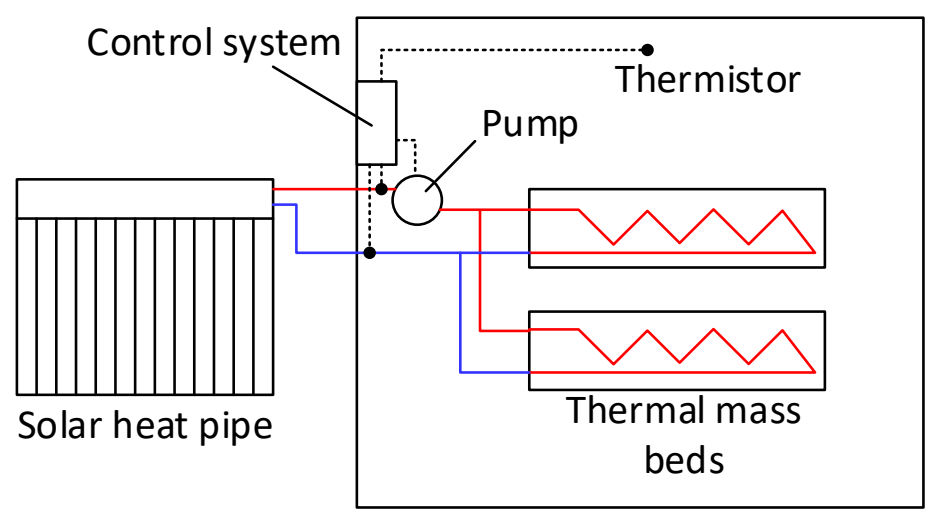

Greenhouse

Fig. 2: Schematic diagram of the solar heat pipe greenhouse system.

A schematic diagram is presented in Fig. 2. Storing heat energy in a thermal mass provides the greenhouse with a relatively steady supply of heat in order to stabilize temperature in the greenhouse. The water/propylene glycol mix was pumped through the solar thermal collector to transfer the collected thermal energy to concrete slabs. PEX tubes to carry the fluid from the collector to the greenhouse were insulated polyethylene pipe insulation. The tubing splits through two 10 $\mathrm{ft}$ by $1 \mathrm{ft}$ by $1 \mathrm{ft}$ concrete slabs. The slabs were poured in three 4 -in-layers of concrete with coils of PEX tubing laid between each layer.

A controller was programmed to maintain the temperature of the greenhouse at $80-85^{\circ} \mathrm{F}$, using the greenhouse inside temperature and the temperature of the glycol being supplied to the thermal mass. The control system consists of the greenhouse, the main circulating pump, the controller, and the temperature sensors. Three temperature sensors were placed: two thermistor sensors in the solar collector both on the supply and the return side and a thermistor sensor in the greenhouse to decide power supply to the pump. The pump circulates the water/glycol $\mathrm{mix}$ at $2.2 \mathrm{gal} / \mathrm{min}$.

\section{Test Results}

The first iteration of data collected from the greenhouse was made to determine the rate of heat collection from the solar heat pipe. The temperatures of the water-glycol mix at the supply $\left(T_{\mathrm{s}}\right)$ and return $\left(T_{\mathrm{r}}\right)$ sides of the solar heat pipe vacuum collector were recorded at a constant flow rate of 2.2 gal per minute. The data were stored every 15 minutes. The data for a two-hour period in April 16, 2017 are presented in Table 1. According to the NOAA online weather data provided by National Weather Service Forecast Office [10], the maximum and minimum temperatures of the day were recorded $49^{\circ} \mathrm{F}$ and $23^{\circ} \mathrm{F}$. It was partially cloudy with no snow precipitation. Table 1 shows that both the supply and return line temperatures gradually increased. The increments slightly fluctuated due to the changing solar radiation condition. The average temperature difference between the supply and return line was $25.4^{\circ} \mathrm{F}$. With the constant volumetric flow rate, the specific heat of $0.85 \mathrm{BTU} / \mathrm{lb}-{ }^{\circ} \mathrm{F}$ and the density of $8.43 \mathrm{lb} / \mathrm{gal}$, a total heat transfer of about 24,000 BTU/hr is calculated.

Table 1: Graph of supply and return temperatures $\left({ }^{\circ} \mathrm{F}\right)$.

\begin{tabular}{|c|c|c|c|c|c|c|c|c|}
\hline Time & $4: 00 \mathrm{pm}$ & $4: 15 \mathrm{pm}$ & $4: 30 \mathrm{pm}$ & $4: 45 \mathrm{pm}$ & $5: 00 \mathrm{pm}$ & $5: 15 \mathrm{pm}$ & $5: 30 \mathrm{pm}$ & $5: 45 \mathrm{pm}$ \\
\hline$T_{\mathrm{r}}$ & 125 & 130 & 133 & 138 & 143 & 143 & 148 & 154 \\
\hline$T_{\mathrm{s}}$ & 145 & 155 & 160 & 165 & 170 & 170 & 175 & 177 \\
\hline$T_{\mathrm{s}}-T_{\mathrm{r}}$ & 20 & 25 & 27 & 27 & 27 & 27 & 27 & 23 \\
\hline
\end{tabular}

Fig. 3 shows the greenhouse temperature and the outside air temperature when the solar heat pipe was disconnected, which means no heat was supplied from the solar heat pipe. The temperature data were recorded from 5:30 pm April 19, 2017 to 3:30 pm next day. The greenhouse temperature showed a sinusoidal temperature profile that matched the external temperature pattern with a constant temperature difference. The average difference between the greenhouse and outside air temperatures was $28.3^{\circ} \mathrm{F}$. The difference increased to $31.4^{\circ} \mathrm{F}$ between $3: 30 \mathrm{am}$ and $6: 30 \mathrm{am}$. During the period of time, the outside temperature dropped to the lowest, but the greenhouse temperature was maintained relatively constantly at around 
$55^{\circ} \mathrm{F}$. This was due to the heat release from the thermal mass (the concrete slabs). Although heat was not supplied to the thermal mass, it continuously dissipated the stored heat and helped maintain the greenhouse temperature. The temperature difference became smaller in the next day morning. While heat loss happened through the greenhouse walls, roof and floor by conduction and convection, the incident solar radiation through the grazing slowed down the decrease in the temperature difference.

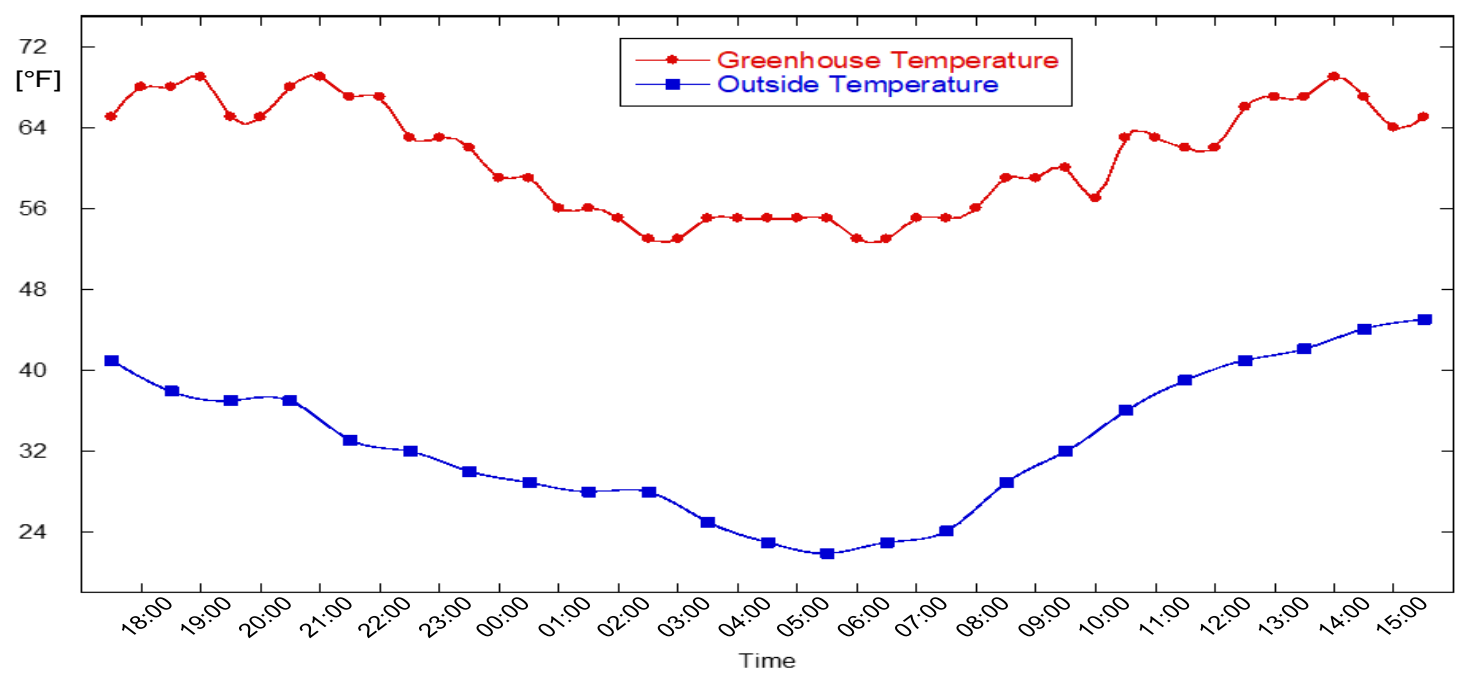

Fig. 3: Greenhouse and outside air temperatures when the solar heat pipe was disconnected (5:30 pm April 19, 2017 to 3:30 pm April 20, 2017).

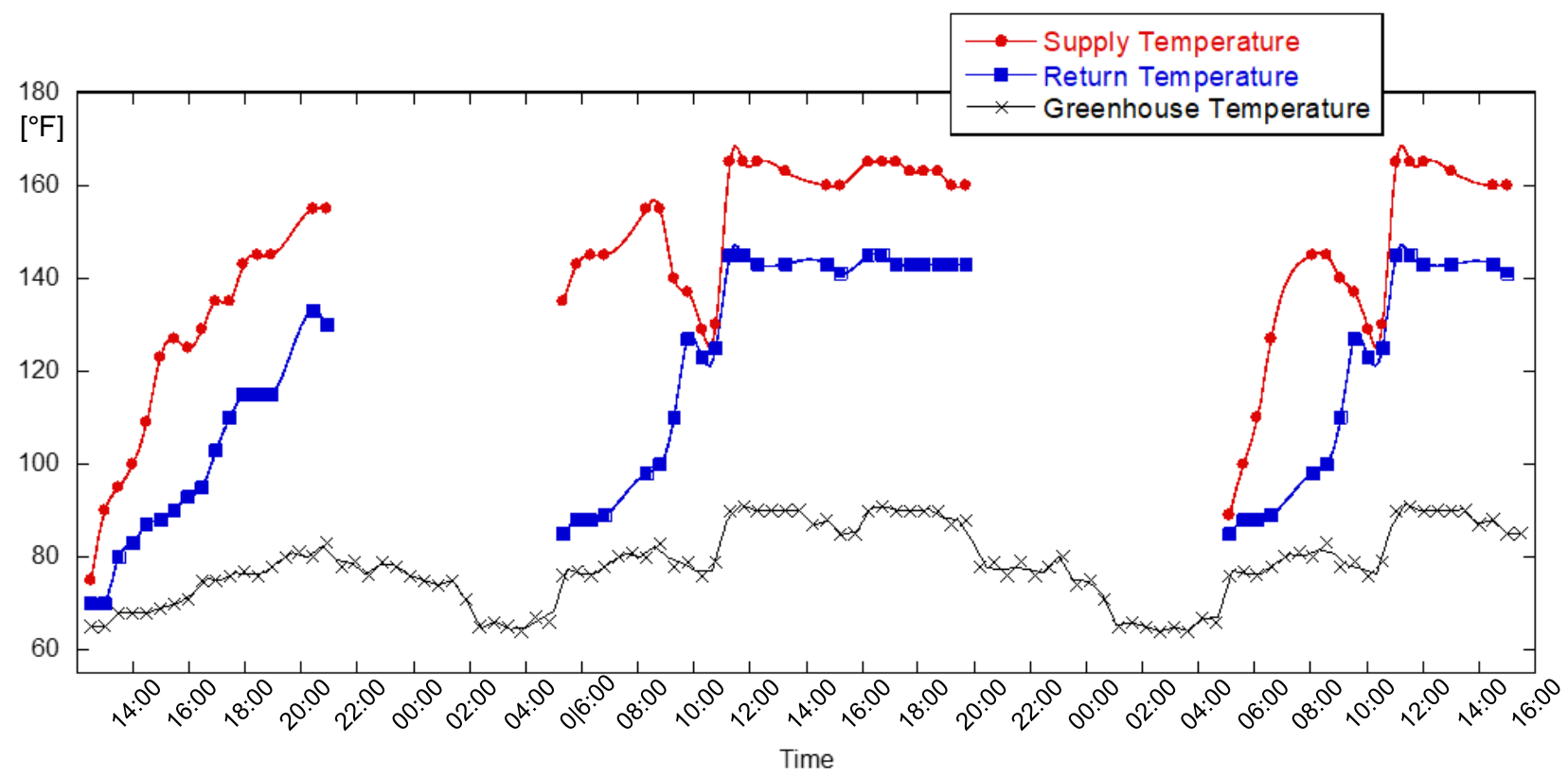

Fig. 4: Temperature history of supply and return lines with the greenhouse temperature when the solar heat pipe was connected (12:30 pm April 21, 2017 to 3:30 pm April 23, 2017).

Figs. 4 and 5 depict the temperature data sets when the solar heat pipe was connected and supplied heat to the greenhouse. The data collection was conducted from 11:30 am April 21, 2017 to 17:30 pm April 23, 2017. On April 22, the sunset and sunrise time were 5:55 am and $9.46 \mathrm{pm}$. A dynamic control program switched on and off the heat supply from the solar heat pipe. The control program stoped heat supply when no solar radiation was available and when the greenhouse temperature reached the upper limit of $90^{\circ} \mathrm{F}$. In Fig. 4, the temperature data for the supply and return sides of 
the solar heat pipe were recorded only when the heat supply was on (or when the controller switched on the pump). Initially, the solar heat pipe had not supplied heat to the thermal mass in the greenhouse until 12:00 pm April 21. A transient heating response was shown on the first day. On the second and third more regular responses were observed. From the beginning of operation on day 1, the supply-to-return temperature difference increased as the solar heat pipe collected the solar radiation. Thermal energy was stored in the thermal mass until around 6:00 pm. After sunset, the greenhouse temperature gradually decreased. The lowest and highest of the greenhouse temperature were about $65^{\circ} \mathrm{F}$ and about $90^{\circ} \mathrm{F}$, respectively. On the first day the average internal-to-external temperature difference was $33.8^{\circ} \mathrm{F}$. After the first day the average temperature difference rose to $39.5^{\circ} \mathrm{F}$ because the internal temperature reached and plateaued at the target high temperature. The average supply-to-return temperature difference was $25.01^{\circ} \mathrm{F}$. This implies an average heat transfer rate of approximately $23,700 \mathrm{BTU} / \mathrm{hr}$ while the pump was turned on. For the 24 hours of April 22, the pump was running for about 12 hours. This results in the total heat supply of the solar heat pipe, 285,000 BTU for the day. It stopped pumping the fluid from the solar heat pipe around at 7:00 pm, which was about 2 hours prior to the sunset. The controller disconnected the power to the pump because the greenhouse temperature reached the set maximum value.

Fig. 5 is the graph for the greenhouse and outside air temperatures for the same period of time as in Fig. 4. On the first day the average internal-to-external temperature difference was $33.8^{\circ} \mathrm{F}$. After the first day the average internal-to-external temperature difference rose to $39.5^{\circ} \mathrm{F}$ because the internal temperature reached and plateaued at the target high temperature. The temperature difference when no heat addition from the solar heat pipe was made was $28.3^{\circ} \mathrm{F}$ from Fig. 3 . Assuming all other conditions remained the same, the use of the solar heat pipe increased the value by $11.2^{\circ} \mathrm{F}$. The main goal of this extended season greenhouse, to maintain a reasonable growing temperature between $60^{\circ} \mathrm{F}$ and $90^{\circ} \mathrm{F}$, was achieved.

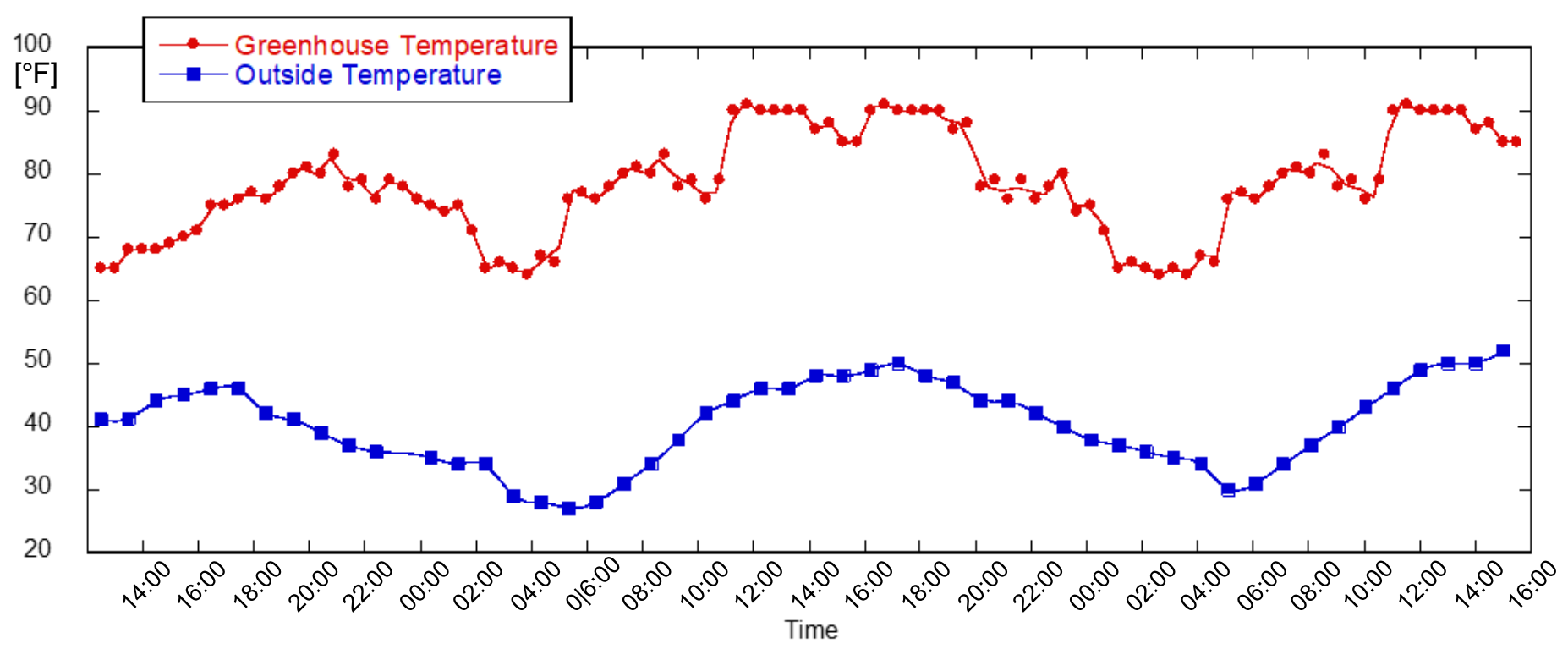

Fig. 5: Temperature history of the greenhouse air and outside air when the solar heat pipe was connected (12:30 pm April 21, 2017 to $3: 30$ pm April 23, 2017).

\section{Conclusion}

The use of a solar heat pipe vacuum collector and thermal mass was examined for its potential to extend the growing season in the arctic and subarctic regions. A test greenhouse of $10 \mathrm{ft}$ by $10 \mathrm{ft}$ with a height of 6 to $8 \mathrm{ft}$ was constructed in Fairbanks, Alaska. A control system was adopted for the regulation of fluid flow and keeps the greenhouse within a growing temperature range. Performance tests were conducted in April 2017. The summary of this research is as follows:

1. The solar heat pipe vacuum collector conversed the incident solar radiation to heat transfer at a rate of about $24,000 \mathrm{BTU} / \mathrm{hr}$. With a rough estimate of 12 hours of solar radiation a day in April in Fairbanks AK, it can provide 288,000 BTU a day. 
2. The solar heat pipe with thermal mass system tested in the present study increased the average greenhouse temperature by about $11^{\circ} \mathrm{F}$. This implies that the growing season can begin 28 days earlier in spring and last 27 days longer in fall (Calculations are based on the time elapsed for the average low temperature of Fairbanks from $32^{\circ} \mathrm{F}$ to $43^{\circ} \mathrm{F}$ in spring and from $43^{\circ} \mathrm{F}$ to $32^{\circ} \mathrm{F}$ in fall).

3. The control system was able to maintain the greenhouse within a growing temperature range of $60^{\circ} \mathrm{F}$ to $90^{\circ} \mathrm{F}$.

4. The control system stopped the flow of the heat transfer fluid about two hours prior to the sunset time. This can be a longer period of time if more solar radiation is available. The heat storage capacity of the thermal mass should be improved to fully utilize the solar radiation.

\section{Acknowledgements}

The authors acknowledge the financial support from the Review of Infrastructure, Sustainability, and Energy Board at the University of Alaska Fairbanks, the ASME Northern Alaska Subsection and SIEMENS. Special thanks go to Dr. Deben Das at UAF.

\section{References}

[1] The Alaska Climate Research Center, Fairbanks Seasonal/Annual Summaries. [Online]. Available: http://climate.gi.alaska.edu/Climate/Fairbanks

[2] P. A. Loring and S. C. Gerlach, "Food, culture, and human health in Alaska: an integrative health approach to food security," Environmental Science and Policy, vol. 12, no. 4, pp. 466-478, 2009.

[3] D. V. Fazzino and P. A. Loring. "From crisis to cumulative effects: food security challenges in Alaska," Annals of Anthropological Practices, vol. 32, no. 1, pp. 152-177, 2009.

[4] M. Santamouris, A. Argiriou, and M. Vallindras, "Design and operation of a low energy consumption passive solar agricultural greenhouse," Solar energy, vol. 52, no. 5, pp. 371-378, 1994.

[5] N. L. Panwar, K. Surendra and S. C. Kaushik, "Cost-benefit and systems analysis of passively ventilated solar greenhouses for food production in arid and semi-arid regions," Environment Systems and Decisions, vol. 34, no. 1, pp. 160-167, 2014.

[6] W. M. El-Maghlany, A. T. Mohamed, and T. Hiroshi, "Optimum design and orientation of the greenhouses for maximum capture of solar energy in north tropical region," Energy Conversion and Management, vol. 105, pp. 1096-1104, 2015.

[7] J. A. Fay and D. S. Golomb, Energy and the environment. Oxford University Press, New York, 2012.

[8] B. Bellows, "Solar Greenhouses," ATTRA National Sustainable Agriculture Information Service. 2003. [Online]. Available: http://citeseerx.ist.psu.edu/viewdoc/download?doi=10.1.1.372.7647\&rep=rep1\&type=pdf

[9] Apricus Solar Company, Evacuated tube solar collector, ETC-30C. [Online]. Available: http://www.apricus.com/en/america/products/solar-collectors/ap-30c-buy-american-collector/\#.WhR2MWjWzDc

[10] National Oceanic and Atmospheric Administration, National Weather Service: Past weather in Fairbanks, Alaska. [Online]. Available: http://w2.weather.gov/climate/index.php?wfo=pafg 